Canadian

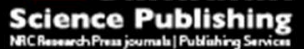

Canadian Journal of Civil Engineering Revue canadienne de génie civil

\title{
Analysis of stresses in concrete pavement under a dowel according to its diameter and Load Transfer Efficiency
}

\begin{tabular}{|r|l|}
\hline Journal: & Canadian Journal of Civil Engineering \\
\hline Manuscript ID & cjce-2014-0110.R2 \\
\hline Manuscript Type: & Article \\
\hline Date Submitted by the Author: & 07-Jul-2015 \\
\hline Complete List of Authors: & $\begin{array}{l}\text { Mackiewicz, Piotr; Wrocław University of Technology, Institute of Civil } \\
\text { Engineering }\end{array}$ \\
\hline Keyword: & $\begin{array}{l}\text { computational methods < type of paper to review, structure - concrete }< \\
\text { Struct.Eng. \& Constr.Mate, computational mechanics < Engineering } \\
\text { Mechanics, fracture; fatigue and dam < Engineering Mechanics, theoretical } \\
\text { analysis < type of paper to review }\end{array}$ \\
\hline
\end{tabular}


Analysis of stresses in concrete pavement under a dowel according to its diameter and Load

\section{Transfer Efficiency}

Piotr Mackiewicz

Wrocław University of Technology, Institute of Civil Engineering, Wyb. Wyspiańskiego 27, 50-370

Wrocław, Poland

piotr.mackiewicz@pwr.wroc.pl 


\section{Abstract}

The suitable load transfer between adjacent concrete slabs in transverse joint is influenced by various parameters. In this paper, the influence of different diameters and spacing of dowel bars on the slab interaction was considered. Calculations were carried out with application of 3D Finite Element Method. Verification of the model was performed with the concrete pavement in Poland. Results of these calculations were compared with falling weight deflectometer (FWD) studies. Calculations of stress concentration around dowel bars for different conditions and parameters enabled to determine a relationship between Load Transfer Efficiency (LTE) and vertical compressive stresses in the concrete slab. It was found that application of dowels with small diameters can promote damages in the concrete slab because of concentration of vertical compressive stresses under the dowel bar. The found relationship enable to determine stresses in concrete under the dowel according to its diameter and LTE.

Keywords: jointed plain concrete pavement (JPCP), dowel bars, Finite Element Method (FEM), vertical compressive stress, Load Transfer Efficiency (LTE) 


\section{Introduction}

The interaction in jointed plain concrete is a complex phenomenon. When the slab of pavement is loaded, it is deflected together with dowels, which connect the loaded slab with the adjacent slab. During this process, the dowels transfer part of the load to the unloaded slab. This mechanism depends mainly on the modulus of dowel support which can be determined by load testing (Yoder and Witczak, 1975). The high modulus of dowel support indicates a tight contact between the steel dowel and the surrounding concrete. The efficiency of interaction between slabs is expressed as Load Transfer Efficiency (LTE). This parameter depends on many factors, e.g. number of dowel spacing, dowel diameter, thickness of slab and joints as well as parameters of layers located under the concrete slab. A wrong location of dowels and corrosion can also influence the LTE substantially.

The first calculations of the compressive bearing stress induced by a dowel bar was performed by Bradbury (1932). He assumed that the dowel is an infinite beam whereas the concrete is Winkler foundation. Using Timoshenko's analysis he found formulas for the length of dowel required for permissible shear, bending and bearing stresses. The analysis by Timoshenko (1925) showed that the general expression for the bar deflection gives a wave curve with gradually diminishing amplitude when the distance from the applied load increases. Assuming the supporting medium as an elastic material, he also found that the intensity of pressure on the bar at any point is proportional to the deflection at this point.

A finite-element analysis has been applied to the pavement design for many years (Zienkiewicz, 1994). Two-dimensional finite-element (2DFE) approach has been used in analyses of rigid pavement response (Huang, 1974; Tabatabai and Barenberg, 1978; Tayabji and Colley, 1981; Huang, 1985). However, the inclusion of the third dimension and development of threedimensional finite-element (3DFE) methods enable to analyse more details in pavement response 
that cannot be considered in the traditional 2DFE studies (Channakeshava et al. 1993; Zaghloul et al. 1994; Davids et al. 1998a).

Although dowels with beam elements meshed within the solid slab have been modelled many times, dowel-slab interaction was not studied in details. One exception is the paper of Channakeshava et al. (1993), who studied the interaction between the dowels and the concrete using discrete nonlinear springs which connected the ends of the dowels with slabs. Guo et al. (1994) applied a bilinear stiffness model and included contact elements at all possible contact points between the dowel and the concrete. Zaman and Alvappillai (1995) studied the effect of dowel-concrete interaction considering the dowel length. Other approaches were developed by loannides and Korovesis (1992) and Brill and Guo (2000). The distribution of stresses around the dowel sockets for selected cases of pavement were analysed considering temperature (Riad et al. 2009; Mackiewicz 2014).

The 2DFE model developed by Nishizawa et al. (1989) was modified later (Nishizawa et al. 2001) with the development of a 3D element to represent the dowel bar. The segments set in the concrete were represented by solid elements whereas the segment between the two slabs and joint gap region was represented by 3D beam elements. William and Shoukry (2001) used in their analyses dowel bars represented by eight-nodded solid brick elements.

Although many models based on the finite element method were developed for doweled concrete joints, only very few referred to the induced stresses around dowel bars.

Here, we analyzed interaction between concrete slabs and estimated compressive stresses under the dowel in concrete. In these studies, 3DFEM was applied and GAP-contact elements were included in the interaction of concrete dowel and slab with the ground.

Since a wide range of dowel diameters and spacing is used in different countries, the huge variation of these parameters were here considered. For example, according to German 
regulations (ZTV Beton, 2001) dowels should have $0.025 \mathrm{~m}$ diameter and spacing in the range of $0.25-0.6 \mathrm{~m}$. French requirements (SETRA LCPC, 1998) assume $0.020-0.045 \mathrm{~m}$ for diameter and $0.3-0.45 \mathrm{~m}$ for spacing. In England (Road Pavements, 1998) dowels ought to have diameter from 0.020 to $0.032 \mathrm{~m}$ with $0.3 \mathrm{~m}$ spacing. Dowels with diameter from 0.032 to $0.045 \mathrm{~m}$ with spacing from 0.3 to $0.5 \mathrm{~m}$ are used in Poland (GDDP, 2001). According to $\mathrm{ACl}$ (2002), dowels with 0.032 $0.050 \mathrm{~m}$ diameter with $0.3-0.45 \mathrm{~m}$ spacing are proposed. Summarizing, the dowel diameter ranges from 0.020 to $0.045 \mathrm{~m}$ whereas the spacing from 0.25 to $0.6 \mathrm{~m}$. Here, we considered even wider range of these parameters for the diameter and spacing: $0.020-0.050 \mathrm{~m}$ and $0.15-0.7 \mathrm{~m}$, respectively.

\section{Model utilizing FEM (finite-element method)}

The model of jointed plain concrete pavement (JPCP) was worked out in three-dimensional Cartesian coordinate system and corresponded to a selected motorway pavement in Poland, on which FWD studies and load estimations were carried out. The model of the pavement was presented in Fig. 1.

Assumed parameters of pavement layers were verified in FWD studies according to deflection measurements and back-calculation of layer moduli, which were shown in details further. Tab. 1 includes values for material parameters and the thickness of analyzed pavement that were used in the FEM model assuming a linear-elastic model. Interactions of concrete slab with subbase were modelled using appropriate GAP-contact elements whereas conditions of interactions of dowel bars with concrete slab using restricted dowel-concrete extension on pavement (Fig. 2).

The gap element between a dowel and concrete was assumed on the whole surface of dowel in the model. This gap length was $5 \mathrm{e}-4 \mathrm{~m}$ at the joint and decreased linearly to 0 at the dowel end. 
The element considered friction between the dowel and concrete. The coefficient of sliding friction was assumed 0.05 .

In order to analyze gaps, the force method is used to calculate the forces at the gaps. In this approach, each gap is replaced by two forces, equal in magnitude but opposite in direction, which are applied to the two nodes connected by the gap.

In the force method, the matrix equation to be solved can be expressed by Eq. [1]:

$$
[\mathrm{Fg}]\{\mathrm{Rg}\}=\{\mathrm{Xg}\}
$$

where:

[Fg] the flexibility matrix of the structure,

$\{R g\}$ vectors of gap forces,

$\{\mathrm{Xg}\} \quad$ vectors of relative gap displacements.

In order to define $[\mathrm{Fg}]$, a unit force is applied in the gap direction and the relative displacements induced in all gaps are determined.

We also consider a configuration where the effect of the gaps is neglected. The following inequity implies that the $\mathrm{i}^{\text {th }}$ gap is closed:

$$
U_{g}^{i}=U_{2}^{i}-U_{1}^{i}>g_{i} \text { (closed gap) }
$$

where:

gi gap distance,

$\mathrm{U}_{1}^{\mathrm{i}}$ displacement induced by the external force vector $\{\mathrm{R}\}$.

By solving the equation Eq. [2], the gap force vector $\{\mathrm{Rg}\}$ is obtained. Applying these forces to the structure, the relative gap displacement of the $i^{\text {th }}$ gap equals $x_{g}^{i}=-\left(U_{g}^{i}-g_{i}\right)$. Since, the external force vector $\{R\}$ produces $\{U g\}$ displacement vector, whereas the gap forces $\{\mathrm{Rg}\}$ give $-\left(\{U g\}-g_{i}\right)$ then, $(\{R\}+\{R g\})$ produces $\{g\}$. Therefore, the displaced shape of the structure will resume a 
position where the relative displacement for each closed gap remains equal to its prescribed allowable distance.

Load has the shape of circular slab with the diameter $0.32 \mathrm{~m}$ and pressure $0.7 \mathrm{MPa}(=57.5 \mathrm{kN})$. They were localized at the edge of slab in the distance $0.09 \mathrm{~m}$ from the joint. A wide range of spacing $(0.15 \mathrm{~m}-0.7 \mathrm{~m})$ and diameter $(0.02 \mathrm{~m}-0.05 \mathrm{~m})$ of dowel bars were considered. A model without dowel bars was also analysed for comparison. In calculations we used COSMOS/M software (COSMOS/M, 1993; Rusiński, 1994; Rusiński, 2000), which is dedicated to construction analyses in the field of statics as well as linear and non-linear dynamics.

Linear elastic theory was applied in the model. Eight-node voluminal SOLID elements (fig.2) were used to build the finite model and the appropriate analysis was performed to adjust discretization values. Each node has three degrees of freedom, in sum 24 degrees of freedom. This analysis showed that division into about $120000-130000$ elements in dependence of dowels' number gave good convergence of the results. The iterative procedure based on the modified NewtonRaphson method was used in this calculation.

The stiffness matrix was used to determine forces in nodes.

$[3] \quad[K]=[B]^{\top}[D][B] V_{i j k l}$

where:

[B] geometric matrix based on the function of element shape,

[D] matrix of elasticity of isotropic material,

$\mathrm{V}_{\mathrm{ijkl}} \quad$ element volume.

Equilibrium conditions expressed by Eq. [4]:

[4] $[K]\{q\}=\{F\}$

where:

[K] structural stiffness matrix, 
\{q\} vector of nodal displacements,

\{F\} load vector.

Using kinematic boundary conditions we obtain system of equations

$[\mathrm{K}] \quad[\mathrm{K}]\{\mathrm{q}\}=\left\{\mathrm{R}_{\mathrm{f}}\right\}$

where:

$\left\{R_{f}\right\} \quad$ vector of constant terms.

Fixing was used at the bottom of pavement model in all directions $[u, v, w]^{\top}=0$, whereas displacements on side planes were allowed only in vertical direction $[u, v]^{\top}=0$. where:

$u \quad$ displacement in the $x$ axis

w displacement in the $y$ axis

$v \quad$ displacement in the $z$ axis

Vector of node parameters can be obtained from solution of equilibrium conditions. Next, values of displacement, strains and stress in particular nodes were determined.

Vector of displacements $\{U\}$ is dependent on the matrix of the element shape function $[N]$ and vector of nodal displacements $\{q\}$.

$[6] \quad\{U\}=[N]\{q\}$

where:

$\{U\}=[u, v, w]^{\top}$,

$[N]=[1, x, y, z, x y, x z, y z, z y z]$

Relationship between displacements and strains is given by:

[7] $\quad\{\varepsilon\}=[B]\{\mathrm{q}\}$

Basic equations of elastic theory were used in final calculations:

[8] $\quad\{\varepsilon\}=[D]^{-1}\{\sigma\}$ 
$[9]\left[\begin{array}{llllll}\varepsilon_{x} & \varepsilon_{y}, & \varepsilon_{z} & \gamma_{x y} & \gamma_{y z} & \gamma_{z x}\end{array}\right]^{\top}=[\mathrm{D}]^{-1}\left[\begin{array}{llllll}\sigma_{x} & \sigma_{y} & \sigma_{z} & \tau_{x y}, & \tau_{y z} & \tau_{z x}\end{array}\right]^{\top}$.

\section{Model verification in FWD studies}

The 3D FEM model was verified based on FWD studies on the selected jointed plain concrete pavement. The pavement was characterized by following geometric parameters:

- width and length of the slab: $3.5 \mathrm{~m} \times 4.5 \mathrm{~m}$,

- thickness of the slab: $0.25 \mathrm{~m}$,

- diameter of dowel bars $0.03 \mathrm{~m}$,

- length of dowel bars $0.5 \mathrm{~m}$,

- spacing of dowel bars $0.23 \mathrm{~m}$.

FWD studies were carried out on the road with the length of about $4 \mathrm{~km}$. Measurements of bending and analysis of deep layers enabled to determine material parameters of the particular layers using back-calculation (Szydło, 1995). In FWD studies, air temperature $28-32^{\circ} \mathrm{C}$ was applied. Parameters of layers (moduli) were determined by back calculation for 36 sites in the distance of 4 km. In Fig. 3 values of these moduli for the selected measuring segment were presented. Average values for this distance were included in the 3DFEM model.

Besides typical studies on slab centers, 36 measurements on slab edges were performed. Load on the slab was applied near the edge of concrete slab as shown in Fig. 4. Geophone "D300" and „D200" allowed to measure bending at neighbouring concrete slab edges. 
The deflection bowl measured in FWD studies was compared with FEM calculations. In Fig. 5 and Tab. 2, results of FWD studies and FEM calculations along concrete slabs are shown. In Tab. 2, FEM calc. correspond to the bowl obtained from 3DFEM calculations, whereas FWD test indicates the deflection bowl averaged over 36 measurements on the distance of $4 \mathrm{~km}$. The FEM calc. bowl (fig. 5) was shown by the line and the FWD test bowl by points with whiskers indicating mean and the range of measurements, respectively. We found a very good agreement of the experimental results with the assumed model. Percentage error was in the range of $1 \%$ to $7 \%$. Correlation coefficient between these results was very high and equals 0.9986 .

\section{Results of FEM calculations}

The verified computational model was subjected to more detailed analyses including variable diameter $(0.02 \mathrm{~m}-0.05 \mathrm{~m})$ and spacing $(0.15 \mathrm{~m}-0.7 \mathrm{~m})$ of dowel bars. Other parameters such as: moduli, thickness of layers, connection of the slab with lower layers and load stayed unchanged.

In Fig. 6, an example of deflection bowl for 14 dowel bars with diameter of $0.03 \mathrm{~m}$ and spacing $0.23 \mathrm{~m}$ was shown. Deflections in cross section of pavement were included: in axis of the load and at the edges of two concrete slabs. For comparison, results for 22 dowel bars with diameter of $0.05 \mathrm{~m}$ and spacing $0.15 \mathrm{~m}$ were presented in Fig. 7, whereas without dowels in Fig. 8. Results for other cases were shown in longitudinal section of pavement including variable dowels spacing (Fig. 9) and diameter (Fig. 10).

It can be noticed that interaction between slabs increases with the larger number of dowels in the slabs (i.e. with smaller spacing). Moreover, with the increase in dowels' diameter, deflections of the loaded slab are smaller and interaction between slabs increases. The interaction between slabs is assessed by Load Transfer Efficiency (LTE) Eq. [10]: 


$$
\operatorname{LTE}=\left(\delta_{U} / \delta_{L}\right) \cdot 100 \%
$$

where:

$$
\begin{aligned}
& \text { LTE Load Transfer Efficiency [\%], } \\
& \delta_{U} \quad \text { deflection on the unloaded slab [m], } \\
& \delta_{L} \quad \text { deflection on the loaded slab [m]. }
\end{aligned}
$$

LTE equalled $85.12 \%$ in FEM analyses for 14 dowel bars with the diameter of $0.03 \mathrm{~m}$ and spacing $0.23 \mathrm{~m}$, whereas in FWD studies it was $82.01 \%$ on average. In the second case, it was expressed as the ratio of geophone deflections D300 to D200. The results indicate that the analyzed motorway pavement is ensured by a good interaction between concrete slabs. The relationship between LTE calculated in FEM model for different diameters and spacing of dowel bars is presented in Fig. 11. An appropriate interaction at the level about $80 \%$ between slabs can occur for following examples: - 14 dowels with diameter $0.02 \mathrm{~m}$ and spacing $0.23 \mathrm{~m}$ for $\mathrm{LTE}=82.84 \%$, - 10 dowels with diameter $0.02 \mathrm{~m}$ and spacing $0.32 \mathrm{~m}$ for $\mathrm{LTE}=79.31 \%$, - 6 dowels with diameter $0.03 \mathrm{~m}$ and spacing $0.50 \mathrm{~m}$ for $\mathrm{LTE}=79.83 \%$, - 4 dowels with diameter $0.05 \mathrm{~m}$ and spacing $0.70 \mathrm{~m}$ for LTE=79.48\%. Although conditions of interaction between slabs are fulfilled in many cases when dowels are used, a contact between dowels and concrete can cause some harmful effects because concentration of stresses can occur in the contact zone. It is worth to notice that suitable choice of diameter and spacing of dowels should be dependent also on stresses appearing in a concrete slab and especially at the contact site between dowel-concrete. Compressive stresses under the dowel in the unloaded concrete slab were analysed based on FEM calculations. A distribution of vertical stresses $\sigma_{\mathrm{y}}$ in FEM model was shown in Fig. 12. 
Calculations were also carried out for other cases. The relationship of compressive stresses in a concrete slab under a dowel for different diameters and spacing of dowel bars was shown in Fig. 13. It is visible that considerable compressive stresses (>10 MPa) appear in a concrete slab under dowel with diameters smaller than $0.025 \mathrm{~m}$ for $\mathrm{LTE}<75 \%$. Local stresses exceeding acceptable stresses in concrete appear also for smaller diameters and weaker interaction. Dowels with $0.03 \mathrm{~m}$ diameters can also have a harmful effect on pavement functioning. Although stresses do not exceed acceptable stresses, they can influence damages in concrete pavement as a result of repeatable load or overloaded vehicles.

Therefore, an application of dowels with small diameters and large spacing should be avoided. The presented analyses were carried out for the selected pavement and will be broadened for other loading conditions and parameters describing pavement and its particular layers, e.g. thickness. The found relationship Eg. [11] presented in Fig. 14 allows to determine vertical compressive stresses in concrete slab under dowel knowing only diameter of dowel and Load Transfer Efficiency (LTE). Correlation coefficient for this relationship was very high $R=0.99522$. This equation can be also used for an estimation of functioning of JPCP that already has damages enhancing in the dowel-concrete interface.

$$
\sigma_{y}=\left(20451 \cdot 10^{4}\right) \cdot d^{-3.9107} \cdot L T E^{(16.5881 \cdot d-4.49472)}
$$

where:

$\sigma_{y} \quad$ compressive stresses in concrete slab under dowel [Pa],

LTE Load Transfer Efficiency [\%],

$d \quad$ dowel's diameter $[\mathrm{m}]$. 


\section{Conclusions}

This study focuses on the nature and magnitude of the stresses at the dowel-concrete interface in rigid pavement joints.

The presented computational FEM model including GAP-contact elements allowed to study stress concentration around dowel bars and estimate an interaction between concrete slabs. The results obtained in the model were compared with analyses in Falling weight deflectometer (FWD) on the selected motorway pavement in Poland. Finally, relationship between LTE and vertical compressive stress of concrete were studied. We can conclude that the application of dowels with small diameters can result in damages in concrete slab because of great concentration of vertical compressive stresses. It is visible that considerable compressive stresses ( $>10 \mathrm{MPa}$ ) appear in a concrete slab under dowel with diameters smaller than $0.025 \mathrm{~m}$ for LTE $<75 \%$. In further stages of pavement using, an effect of dowel looseness can appear, which can weaken interaction between concrete slabs. An appropriate interaction at the level about $80 \%$ between slabs and low compressive stresses can occur for following examples: dowels with diameter $0.03 \mathrm{~m}$ and spacing $<0.50 \mathrm{~m}$ or dowels with diameter $0.05 \mathrm{~m}$ and spacing $<0.70 \mathrm{~m}$.

For analyzed dowel's spacing and diameters, we observed a change of LTE from 95 to $70 \%$. The found relationship (Eq. 12) allows efficiently to determine stresses in concrete under a dowel based on its diameter and LTE.

In future studies in this subject, different arrangement of dowels in pavements and their corrosion should be considered. 


\section{References}

American Concrete Institute (ACl) Committee 325, 2002. Guide for Design of Jointed Concrete Pavements for Streets and Local Roads, ACl 325.12R-02, Farmington Hills, MI: American Concrete Institute.

Bradbury, R.D. 1932. Design of joints in concrete pavements. Proceedings No 12, Highway Research Board.

Brill, D. R., and Guo, E. H. 2000. Load transfer in rigid airport pavement joints. In Proceedings of the 26th International Air Transportation Conference, ASCE, Reston, Va.

SETRA LCPC 1998. Catalogue des Structures Types de Chaussées Neuves, Paris.

Channakeshava, C., Barzegar, F., and Voyiadjis, G. 1993. Nonlinear FE analysis of plain concrete pavement with doweled joints. Journal of Transportation Engineering, ASCE, 119(5), 763-781.

COSMOS/M 1993. Advanced modules user guide, Santa Monica, CA.

Davids, W., and Turkiyyah, G. 1997. Development of embedded bending member to model dowel action. Journal of Structural Engineering, ASCE, 123(10), 1312-1320.

GDDP 2001. Catalogue of typical rigid pavements. Warszawa, (in Polish).

Guo, H., Larson, R. M., and Snyder, M. B. 1994. A nonlinear mechanistic model for dowel looseness in PCC pavements. In Proceedings of the 3rd International Conference on Concrete Pavement Design and Rehabilitation, Purdue Univ., West Lafayette, Ind., 359-371.

Huang, Y. H. 1974. Finite element analysis of slabs on elastic solids. Journal of Transportation Engineering, 100(2), 403-416.

Huang, Y. H. 1985. A computer package for structural analysis of concrete pavements. In Proceedings of the 3rd International Conference on Concrete Pavement Design and Rehabilitation, Purdue Univ., West Lafayette, Ind., 295-307. 
loannides, A. M., and Korovesis, G. T. 1992. Analysis and design of dowelled slab-on-grade pavement systems. Journal of Transportation Engineering, 118(6), 745-768.

Mackiewicz, P. 2014. Thermal stress analysis of jointed plane in concrete pavements. Applied Thermal Engineering, 73(2014), 1167-1174.

Nishizawa, T., Fukuda, T., and Matsuno, S. 1989. A refined model of doweled joints for concrete pavement using FEM analysis. In Proceedings of the 4th International Conference on Concrete Pavement Design and Rehabilitation, Purdue Univ., West Lafayette, Ind.

Nishizawa, T., Koyanagawa, M., Takeuchi, Y., and Kimura, M. 2001. Study on mechanical behavior of dowel bar in transverse joint of concrete pavement. In Proceedings of the 7th International Conference on Concrete Pavements, Orlando, Fla.

Riad, M. Y., Shoukry, S. N., William, G. W., and Fahmy, M. R. 2009. Effect of skewed joints on the performance of jointed concrete pavement through 3D dynamic finite element analysis. International Journal of Pavement Engineering, 10 (4), 251-263.

Road Pavements - Concrete and Cement Bound Materials 1998. Volume 1. Specification for Highway Works.

Rusiński, E. 1994. Finite element method. System COSMOS/M, Wydawnictwa Komunikacji i Łączności, Warszawa, (in Polish).

Rusiński, E. 2000. Advanced finite element method in load-bearing constructions. Oficyna Wydawnicza Politechniki Wrocławskiej, Wrocław, (in Polish).

Szydło, A. 1995. Static identification of parameters of airport pavements. Prace Naukowe Instytutu Inżynierii Lądowej Politechniki Wrocławskiej, Wrocław, (in Polish).

Tabatabai, A. M., and Barenberg, E. J. 1978. Finite-element analysis of jointed or cracked concrete pavements. Transportation Research Record., 671, Transportation Research Board, Washington, D.C., 11-19. 
Tayabji, S. P., and Colley, B. E. 1981. Analysis of jointed concrete pavements, Federal Highway Administration, National Technical Information Service, New York.

Timoshenko, S., and Ledels, J. M. 1925. Applied Elasticity. Westinghouse Technical Night School Press, Pittsburgh, PA.

William, G. W., and Shoukry, S. N. 2001. 3D finite-element analysis of temperature-induced stresses in dowel jointed concrete pavements. International Journal of Geomechanics, 1(3), 291307.

Yoder E. J., and Witczak M. W. 1975. Principles of pavement design, 2nd Ed., Wiley, New York.

Zaghloul, S., White, T., and Kuczek, T. 1994. Evaluation of heavy load damage effect on concrete pavements using three-dimensional, nonlinear dynamic analysis. Transportation Research Record 1449, Transportation Research Board, Washington, D.C., 123-133.

Zaman, M., and Alvappillai, A. 1995. Contact-element model for dynamic analysis of jointed concrete pavements. Journal of Transportation Engineering, 121(5), 425-433.

Zienkiewicz, O., and Taylor, R. 1994. The finite element method-Volume I. McGraw-Hill, New York.

ZTV Beton - STB01 2001. Zusatzliche Technische Vertragsbedingungen und Richtlinien fur den bau von Tragschichten mit hydraulischen Bindemitteln und Fahrbahndecken aus Beton. 
Tab. 1. Material parameters and thickness of studied pavement in the model.

\begin{tabular}{|c|c|c|c|c|}
\hline $\mathrm{Nr}$ & Name & $\begin{array}{l}\text { Modulus of layer } \\
\qquad[\mathrm{Pa}]\end{array}$ & $\begin{array}{c}\text { Poisson ratio } \\
{[-]}\end{array}$ & $\begin{array}{c}\text { Thickness } \\
{[\mathrm{m}]}\end{array}$ \\
\hline 1 & Concrete slab & $3.50 \mathrm{E}+10$ & 0.20 & 0.25 \\
\hline 2 & Dowel bar & $2.10 \mathrm{E}+11$ & 0.30 & - \\
\hline 3 & $\begin{array}{c}\text { Subbase } \\
\text { (cement-stabilized aggregate) }\end{array}$ & $2.90 \mathrm{E}+09$ & 0.30 & 0.25 \\
\hline 4 & $\begin{array}{l}\text { Frost-protection layer } \\
\text { (crushed stones) }\end{array}$ & $1.93 E+08$ & 0.35 & 0.15 \\
\hline 5 & Subgrade & $1.43 \mathrm{E}+08$ & 0.35 & 2.50 \\
\hline
\end{tabular}


Tab. 2. Results of FWD studies and FEM calculations.

\begin{tabular}{lccccccccccc}
\hline Geophones & D1800 & D1500 & D1200 & D900 & D600 & D450 & D300 & D200 & D0 & -D200 & -D300 \\
\hline FEM calc. & $1.72 \mathrm{E}-05$ & $2.71 \mathrm{E}-05$ & $4.06 \mathrm{E}-05$ & $5.79 \mathrm{E}-05$ & $7.88 \mathrm{E}-05$ & $9.06 \mathrm{E}-05$ & $1.03 \mathrm{E}-04$ & $1.21 \mathrm{E}-04$ & $1.15 \mathrm{E}-04$ & $1.02 \mathrm{E}-04$ & $9.31 \mathrm{E}-05$ \\
[m] & & & & & & & & & & & \\
FWD test & & & & & & & & & & & \\
{$[\mathrm{m}]$} & $1.81 \mathrm{E}-05$ & $2.89 \mathrm{E}-05$ & $4.24 \mathrm{E}-05$ & $5.95 \mathrm{E}-05$ & $8.08 \mathrm{E}-05$ & $9.37 \mathrm{E}-05$ & $1.01 \mathrm{E}-04$ & $1.23 \mathrm{E}-04$ & $1.17 \mathrm{E}-04$ & $1.04 \mathrm{E}-04$ & $9.90 \mathrm{E}-05$ \\
Error [\%] & 5.42 & 6.93 & 4.30 & 2.82 & 2.56 & 3.44 & -2.17 & 1.66 & 1.59 & 1.96 & 6.34 \\
\hline
\end{tabular}




\section{List of symbols}

[Fg] the flexibility matrix of the structure

$\{\mathrm{Rg}\} \quad$ vectors of gap forces

$\{\mathrm{Xg}\} \quad$ vectors of relative gap displacements

$\mathrm{g}_{\mathrm{i}} \quad$ gap distance

$U_{1}^{i}$ displacement induced by the external force vector $\{R\}$

LTE Load Transfer Efficiency [\%]

$\delta_{U} \quad$ deflection on the unloaded slab [m]

$\delta_{L} \quad$ deflection on the loaded slab [m]

$\sigma_{y} \quad$ compressive stresses in concrete slab under dowel [Pa]

$d \quad$ dowel's diameter [m]

[B] geometric matrix based on the function of element shape

[D] matrix of elasticity of isotropic material

$\mathrm{V}_{\mathrm{ijkl}} \quad$ element volume

[K] structural stiffness matrix

\{q\} vector of nodal displacements,

\{F\} load vector.

$\left\{R_{f}\right\} \quad$ vector of constant terms

$u \quad$ displacement in the $x$ axis

w displacement in the $y$ axis

$v \quad$ displacement in the $z$ axis 


\section{Figure captions}

Fig. 1. Model of jointed plain concrete pavement (JPCP).

Fig. 2. Elements of GAP-contact in the model.

Fig. 3. Moduli of layers in a selected measuring region in pavement.

Fig. 4. Example of FWD study at edges of concrete slabs.

Fig. 5. Comparison of FWD results with FEM calculations.

Fig. 6. Deflection bowl for 14 dowels $0.03 \mathrm{~m}$ diameter and $0.23 \mathrm{~m}$ spacing.

Fig. 7. Deflection bowl for 22 dowles with $0.05 \mathrm{~m}$ diameter and $0.15 \mathrm{~m}$ spacing.

Fig. 8. Deflection bowl without dowel bars.

Fig. 9. Deflection bowl for different dowels spacing.

Fig. 10. Deflection bowl for different dowels diameters.

Fig. 11. Relationship between LTE and spacing dowels for different diameters of dowel bars.

Fig. 12. Distribution of vertical stresses $\sigma_{y}$ in FEM model (for 14 dowels with $0.03 \mathrm{~m}$ diameter and $0.23 \mathrm{~m}$ spacing).

Fig. 13. Relationship between compressive stresses and LTE in concrete slab under dowel for different diameters and spacing of dowel bars.

Fig. 14. Relationship between stresses in concrete slab under dowel from LTE and diameter of dowel described by equation [11]. 

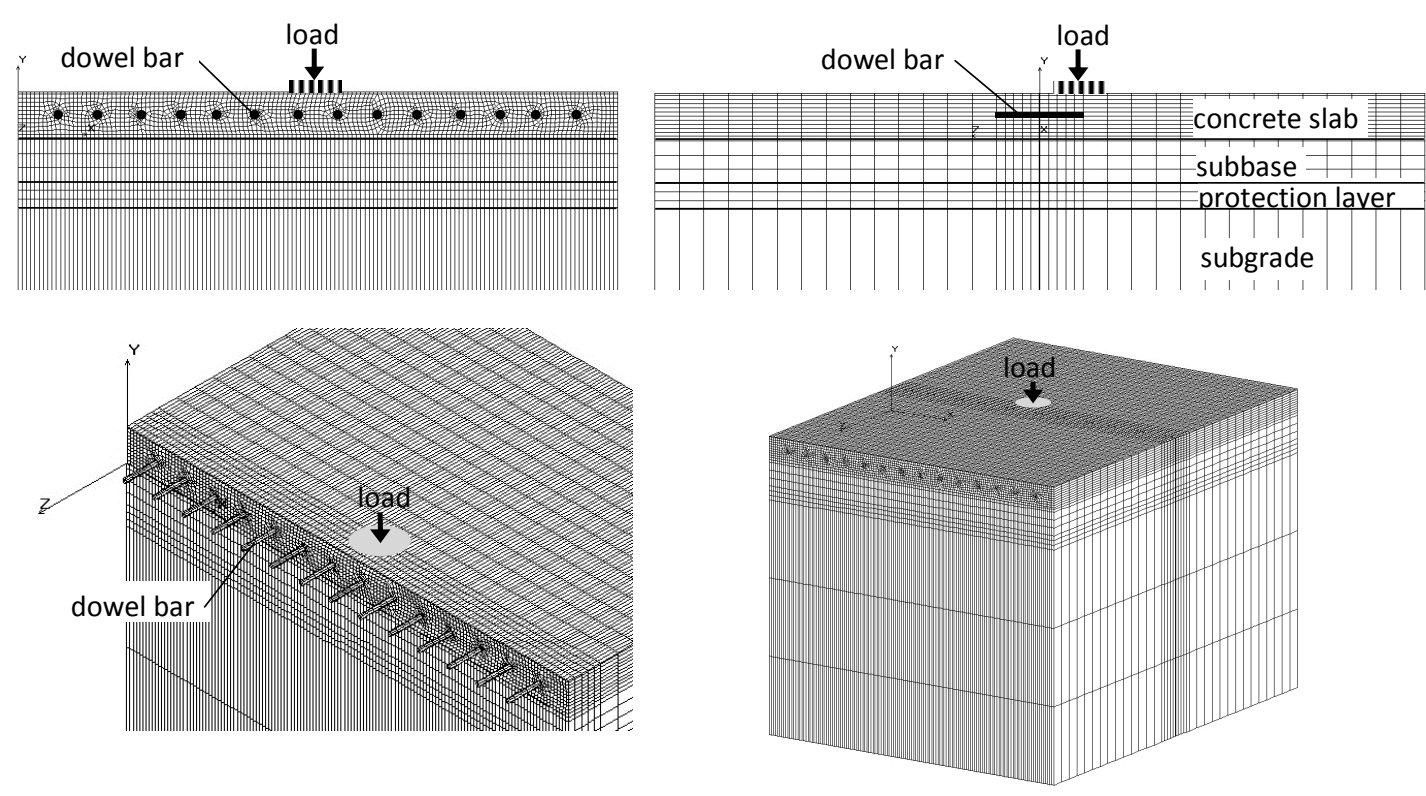

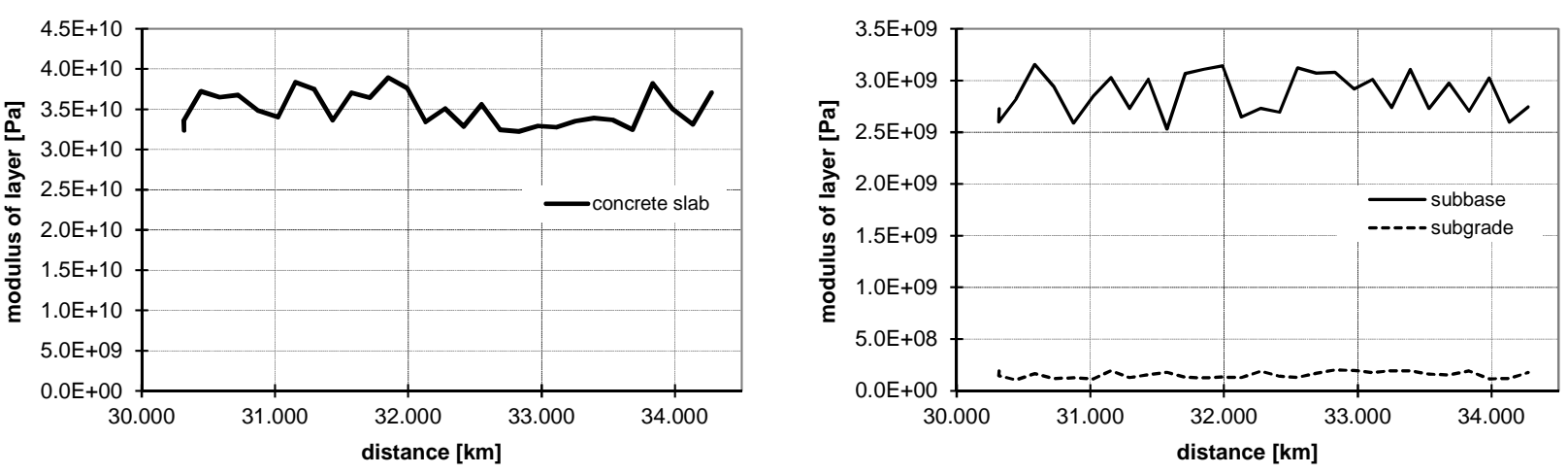


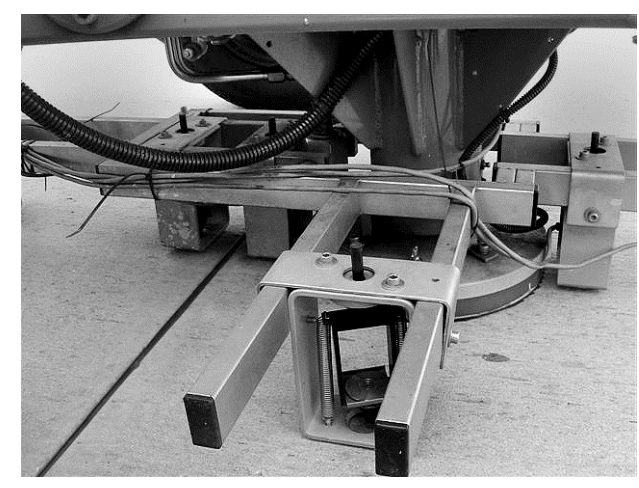

辛量

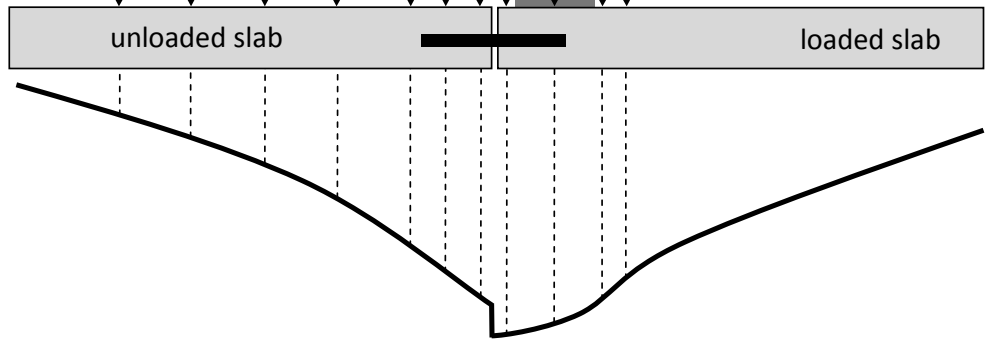




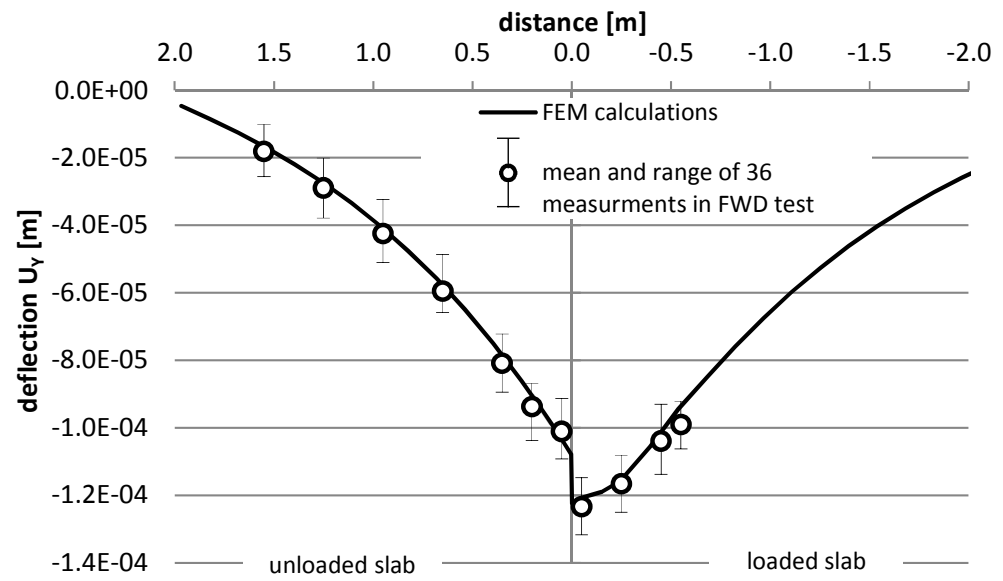



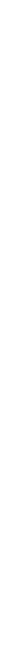


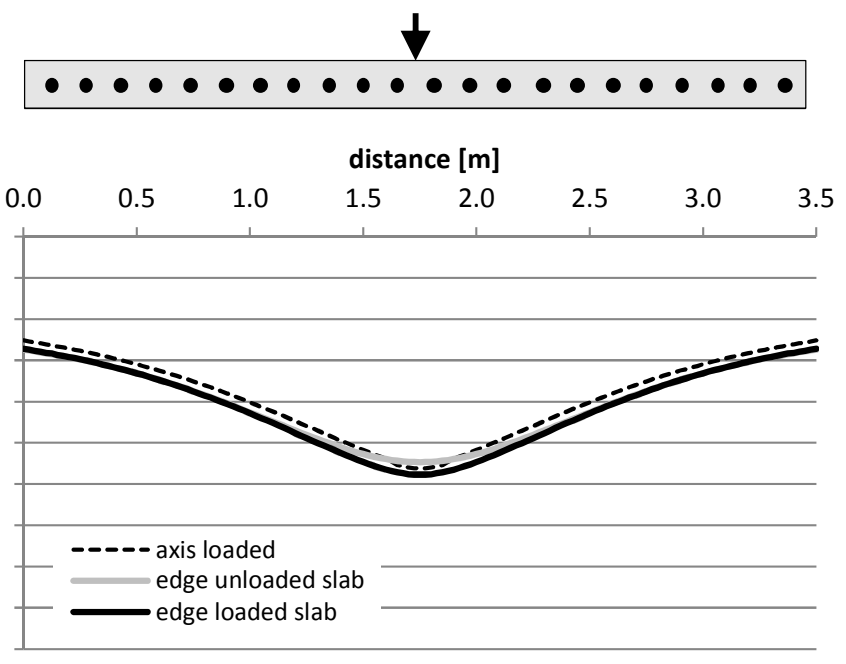



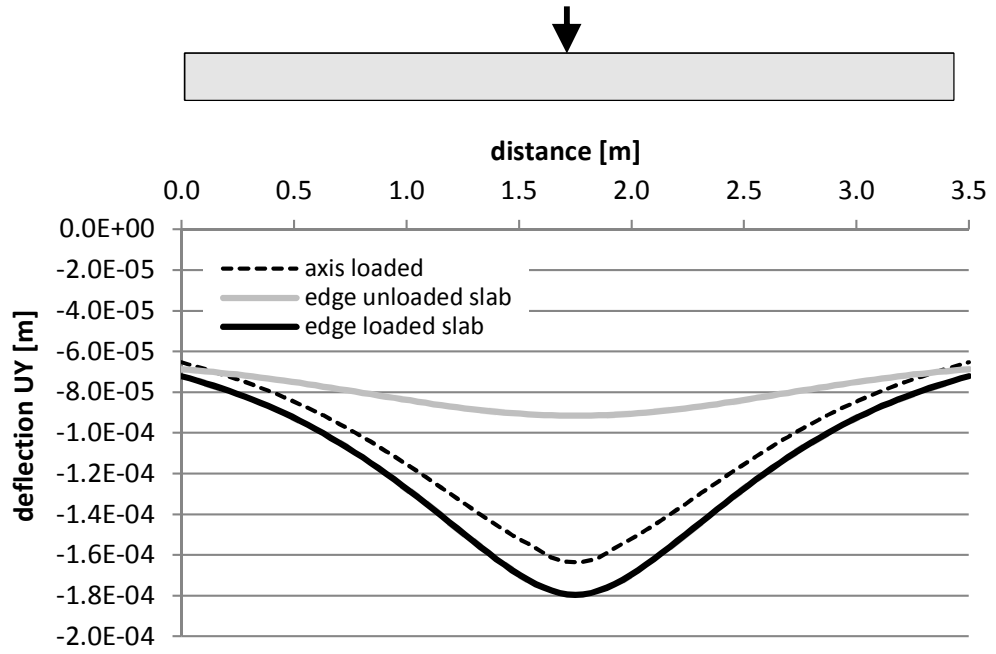


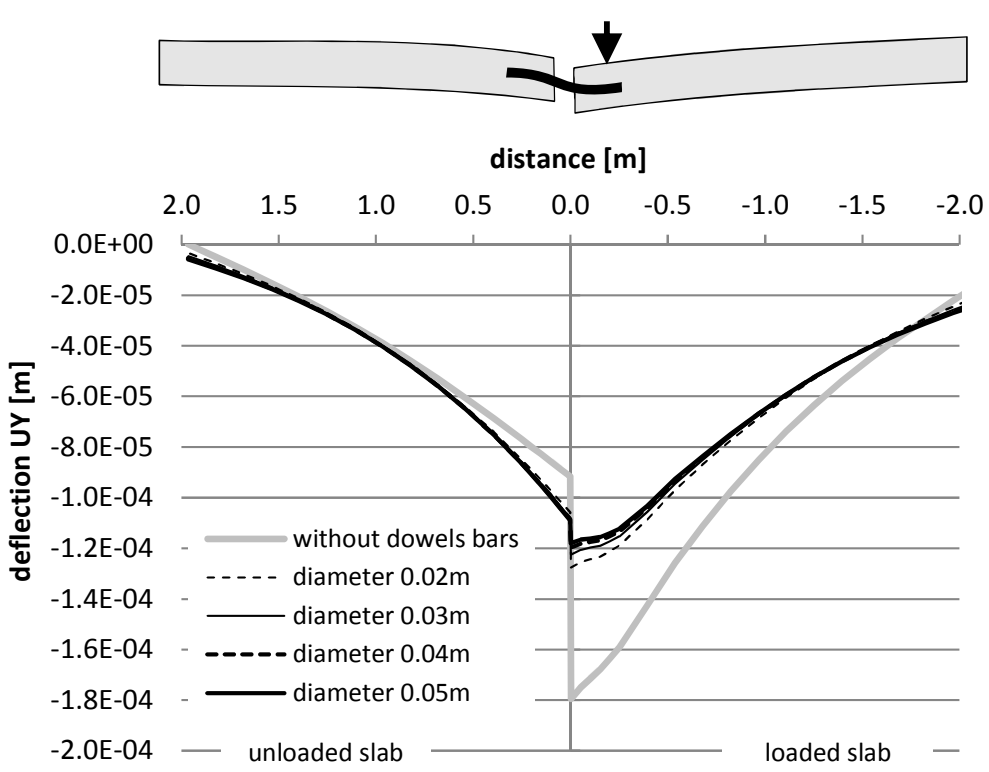




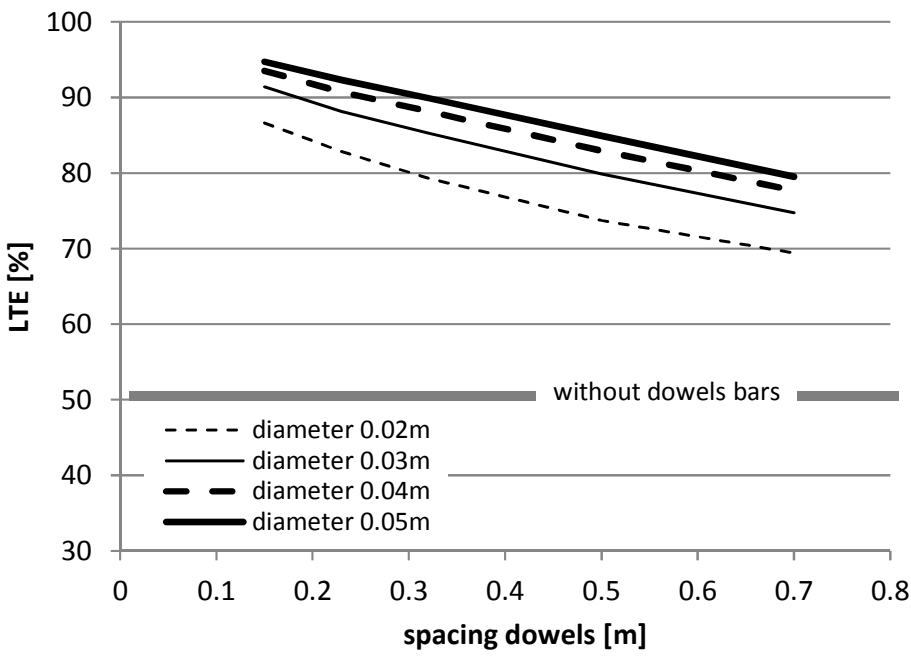




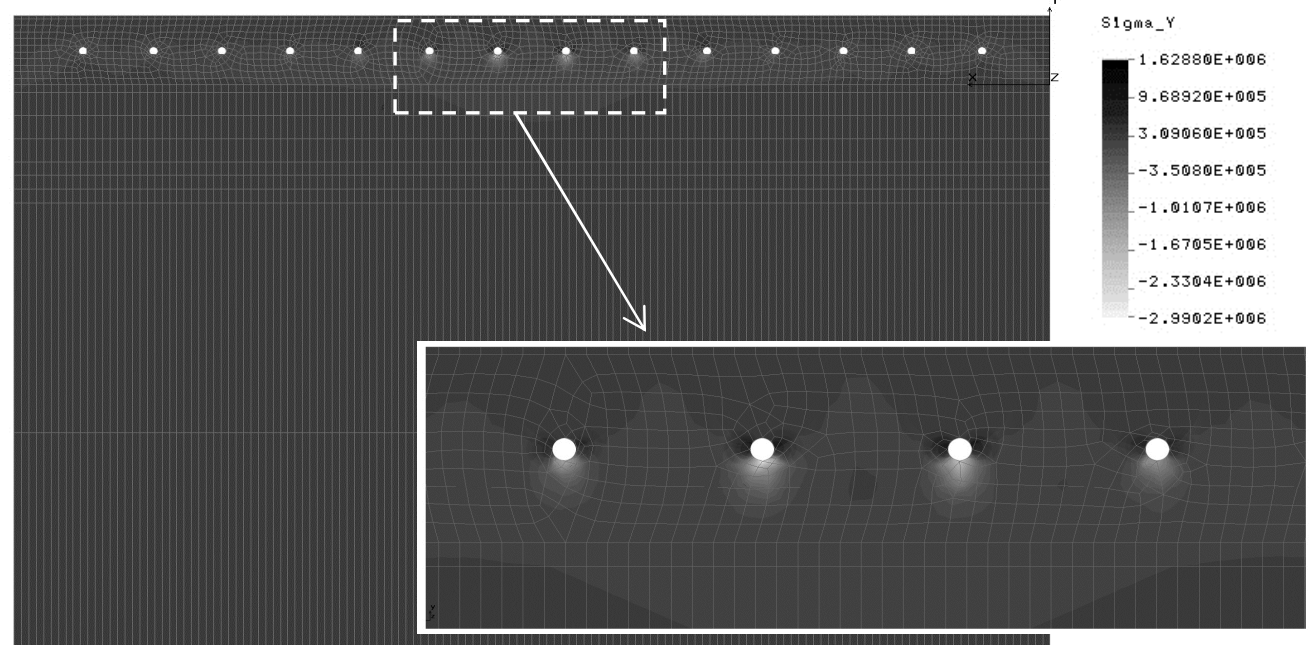




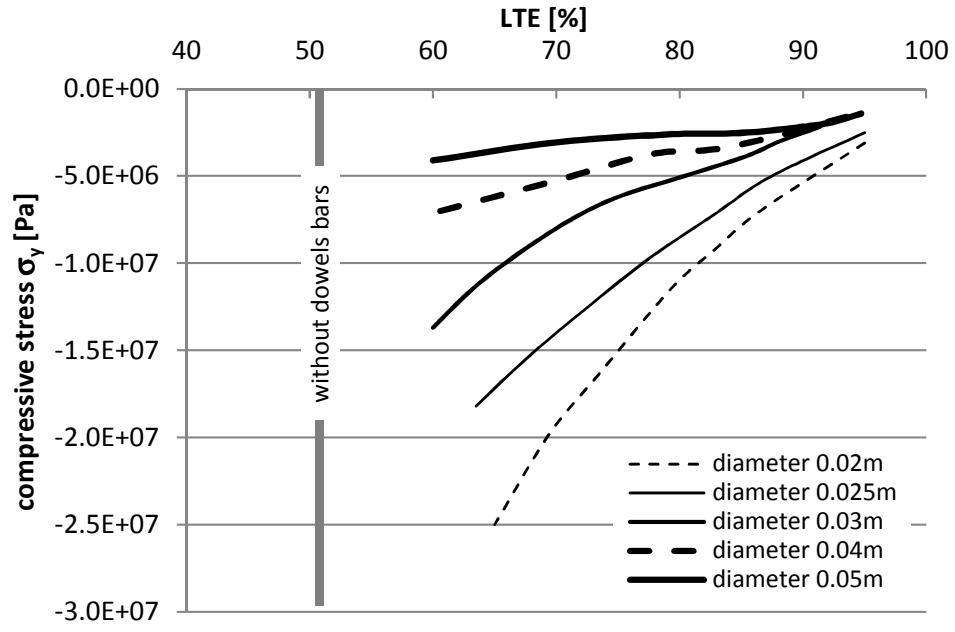




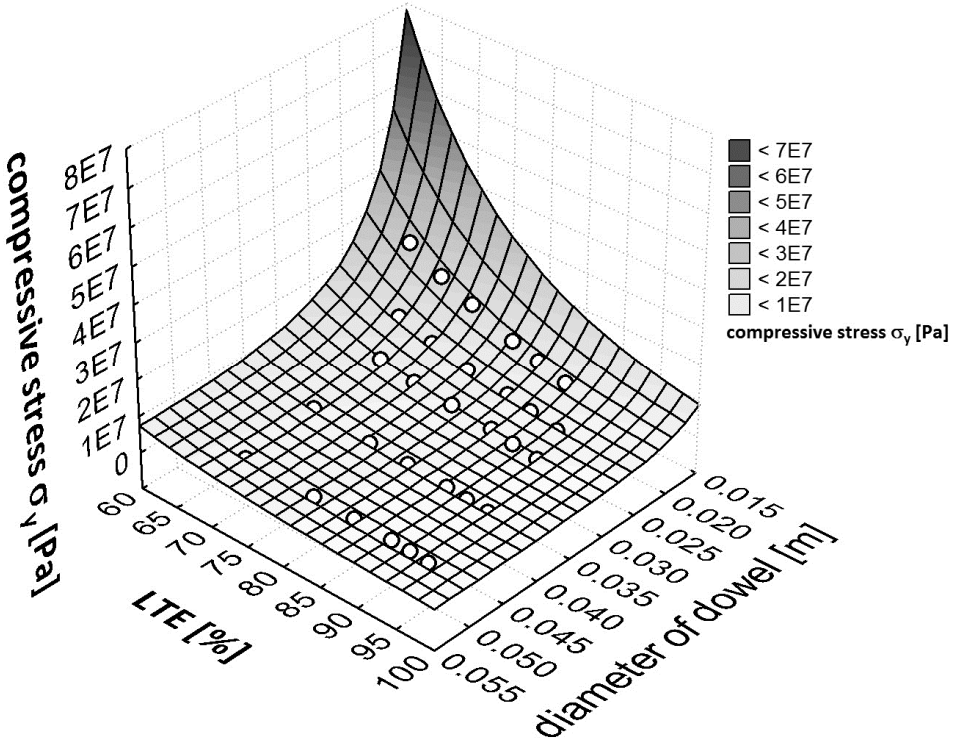

